\title{
A catalog of automated analysis methods for enterprise models
}

\author{
Hector Florez ${ }^{*}$, Mario Sánchez and Jorge Villalobos
}

\author{
*Correspondence: \\ ha.florez39@uniandes.edu.co \\ Department of Systems \\ and Computing Engineering, \\ Universidad de los Andes, \\ Bogotá, Colombia
}

\begin{abstract}
Enterprise models are created for documenting and communicating the structure and state of Business and Information Technologies elements of an enterprise. After models are completed, they are mainly used to support analysis. Model analysis is an activity typically based on human skills and due to the size and complexity of the models, this process can be complicated and omissions or miscalculations are very likely. This situation has fostered the research of automated analysis methods, for supporting analysts in enterprise analysis processes. By reviewing the literature, we found several analysis methods; nevertheless, they are based on specific situations and different metamodels; then, some analysis methods might not be applicable to all enterprise models. This paper presents the work of compilation (literature review), classification, structuring, and characterization of automated analysis methods for enterprise models, expressing them in a standardized modeling language. In addition, we have implemented the analysis methods in our modeling tool.
\end{abstract}

Keywords: Enterprise analysis, Enterprise models, Enterprise architecture, Quantitative analysis, Functional analysis

\section{Background}

Enterprise architecture (EA) encompasses different kinds of elements such as principles, methods, and models, which are used by domain experts in order to provide a holistic view of an enterprise. EA projects are supported on the construction of models that abstract the enterprise for understanding its organizational and technological aspects (Lankhorst 2005); typically, these models are focused on structural aspects of the enterprise, and serve for documentation, communication, diagnosis, analysis, discussion, and design purposes. Enterprise modeling (EM) is the process of creating an integrated enterprise model, which represents certain aspects of the enterprise that are required for the modeling purpose. An enterprise model describes the current or future state of an enterprise and contains the enterprise knowledge of the stakeholders involved in the modeling process (Sandkuhl et al. 2014). Enterprise modeling offers different views of an enterprise, for understanding enterprise systems through proper abstractions (Frank 2014).

When an enterprise model is used to analyze the enterprise, analysis results can be used to support decision making processes, such as planning future states of the enterprise (Buckl et al. 2009); as a result, analysis has become a critical task because it

\section{Springer Open}

(c) 2016 Florez et al. This article is distributed under the terms of the Creative Commons Attribution 4.0 International License (http:// creativecommons.org/licenses/by/4.0/), which permits unrestricted use, distribution, and reproduction in any medium, provided you give appropriate credit to the original author(s) and the source, provide a link to the Creative Commons license, and indicate if changes were made. 
contributes to the improvement of the business and IT elements. Analysis is a complex human activity that involves the formulation of hypotheses and the discovery of insights in order to get assessments. Typically, one analyst manipulates the enterprise model in order to extract information that is useful, for evaluating the state of the enterprise. Nevertheless, the quality of the analysis results depends on three factors: (1) the experience, knowledge, and skills of the analyst; (2) the quality of the models; and (3) the granularity, completeness and level of detail of the information contained in the models. The implementation of automated analysis methods contributes to reduce the risk associated with the first factor.

Automated analysis methods are algorithms that extract information from the model and make calculations. Automating the procedures for extracting and calculating information makes possible to work with the complete model, which can include a large amount of elements and relations. Automated analysis methods might require that the model has some specific information; thus, the metamodel of the modeling language (e.g., ArchiMate) must be adapted in order to demand the required information in the model. The results provided by one analysis method not only are used to provide assessments, but also could be used to enrich the model, for running more complex analysis methods.

In the literature, there are several analysis methods for different purposes (e.g., optimization, performance, and impact of change); however, normally those analysis methods are focused on a particular problem and they are based on different metamodels (e.g., workload of human resources in business processes using BPMN as modeling language, for a commercial enterprise). Then, the analysis method algorithm might be very specialized making it neither applicable nor reusable in other enterprise models. The lack of re-usability becomes an important issue because, when the analyst decides to perform an existing analysis method that was not designed for the enterprise model that is being analyzed, there is the need to modify the analysis method increasing the effort and cost of the analysis process. Moreover, due to analysis methods are taken from multiple references; there is a lack of uniformity, structure, and characterization.

In this work, we have made the compilation, classification, structuring, characterization, and unification of the analysis methods found in the literature review. The result of this work has been collected in one catalog of analysis methods to offer, for each analysis method, a unified characterization, detailed description, required inputs, algorithm, and results. This catalog is also extensible in order to allow the inclusion of new analysis methods. The catalog should serve several purposes. For example, it should assists analysts in the identification of proper analysis methods considering the goals and characteristics of the enterprise that is being analyzed. The catalog also create requirements for modelers, whose goal is to create models that are complete with respect to specific business objectives. Furthermore, the catalog supports stakeholders in identifying certain aspects of the enterprise that matches their concerns.

Although the catalog is intended to be independent of the modeling language, we faced the necessity of selecting a coherent and well-known set of concepts in order to describe the analysis methods. For this purpose we selected ArchiMate, a standardized and well known language based on TOGAF's Architecture Content Framework, which was created around the most commonly concepts used in EA. The modeling tool that we have 
created to implement, experiment and validate the analysis methods found in the catalog is thus based on ArchiMate. By means of this tool we were able to identify specific features for each analysis method, determine the requirements for their execution, design and test the algorithms for each one, and ultimately document them to form the catalog. Moreover, the fact that ArchiMate is founded on generic and common concepts, makes the analysis methods concrete but also as general as they can be. Furthermore, the tool allows adjusting, adapting, or personalizing the ArchiMate metamodel to (1) ensure that the model contains the required information for performing the desired analysis and (2) enrich the model with the analysis methods results. In addition, when the catalog will evolve to including new analysis methods, these will be easily implemented and validated thanks to its extensible architecture. For illustrating the analysis methods of the catalog, we have built an enterprise scenario, which is one publisher of academic books. The enterprise model of this scenario has been built using the tool that we have created; thus, this model is based on ArchiMate as modeling language. It has 184 business elements, 13 application elements, 13 infrastructure elements, 28 motivation elements, and 432 relations arranged in 12 views. This scenario is proper for validating this work because it has several issues that can be solved through performing the analysis methods of the catalog.

The rest of the paper is structured as follows. The next section summarizes concepts regarding enterprise analysis. In the third section, we present the systematic literature review made regarding enterprise analysis. In the fourth section we (1) classify and characterize the analysis methods taken from the literature review, (2) collect them in one catalog of analysis methods for enterprise architecture models based on the ArchiMate modeling language, and (3) illustrate some analysis methods using the experimental enterprise scenario. Then, in the fifth section we present our tool in which we have implemented the analysis methods of the proposed catalog. Finally, the last section concludes the paper.

\section{Enterprise analysis}

Enterprise analysis is the application of property assessment criteria on enterprise models (Johnson et al. 2007). This means that, given an enterprise property and a criterion for assessing that property, doing model analysis requires evaluating said criteria using the information available in the model. Typically, model analyses are performed by humans supported by modeling tools that are used just to get access to the available data in an efficient way. However, analysts have the entire responsibility of discovering information (Florez et al. 2014) useful to provide assessments. On the one hand, this can be an advantage because humans are good at reasoning with incomplete information, but on the other hand, this can be a serious problem because the omission of elements and miscalculation of results, especially in large enterprise models, are very likely.

When the analyst performs an analysis using a modeling tool that is not conditioned for analysis processes, based on the purpose of the analysis, the analyst determines which elements, relations, and attributes are involved. The analyst browses the model using a modeling tool and gets the desired information from the model, in order to obtain the required results that can be included manually in the model. Those results are interpreted by the analyst for providing assessments. 


\section{Automated analysis}

Automated analysis refers to the use of automated analysis methods, for supporting analysts in the analysis process. Automated analysis methods are algorithms that allow extracting and calculating information from the model, for (1) obtaining facts that are results based on the information placed in the model or (2) enriching the model augmenting it with elements, relations, elements' attributes, or relations' attributes in order to provide new useful information.

Analysis methods require that the enterprise model provides sufficient and adequate information; then, the model must have specific required information in its elements or relations that are object of the analysis. Thus, when the purpose of building an enterprise model is analyzing the enterprise, modelers need to know the analysis requirements in order to create the necessary elements, attributes, and relations in the model. The lack of certain elements in the model could result in the impossibility to perform certain analysis methods. For instance, application components depend on infrastructure elements such as devices, system software, and infrastructure services. The availability of each infrastructure element should be $100 \%$; however, in the reality, there are a lot of factors that affect this requirement. Then, the availability of application components must be calculated based on the availability of the related infrastructure elements. Thus, one analysis method, for calculating the availability of application components, requires that the infrastructure elements in the model include their availability. Then, the modeling tool should be able to support and validate this characteristic.

For performing analyses, the analyst executes one analysis method using an Analysis Engine that works on the model and some input parameters provided by the analyst. After executing the analysis method, the Analysis Engine generates results, which are interpreted by the analyst, for communicating assessments.

\section{Analysis dimensions}

Lankhorst (2005) classifies enterprise architecture (EA) analysis approaches using four dimensions represented in a Cartesian plane. On the one hand, the Y-axis makes the distinction between quantitative and functional analysis. On the other hand, the $\mathrm{X}$-axis makes the distinction between simulation and analytical techniques.

Quantitative analysis provides results regarding specific measures of the enterprise model. This analysis serve for several purposes such as optimization (e.g., quantification of the effect of design choices), impact of change (e.g., quantitative effect of changes), or capacity planning (e.g., amount of people required to finish processes on time). Enterprise models can be quantified by different measures such as performance measures that are time-related measures (e.g., response times, throughput), reliability measures (e.g., availability, dependability), or cost measures (e.g., architecture cost, ROI).

Functional analysis provides results that refer to information from functional aspects, which can be static or structural (e.g., structural properties) and dynamic or behavioral (e.g., services or activities). The analysis of static structure focuses on the syntactic i.e., symbolic representation of the elements and its relations. In one EA model, these analyses focus the separation of concerns, which allows managing the complexity of the architecture. The analysis of the dynamics focuses on the formal semantics, and is based on formal approaches such as process algebras and flow networks. Thus, a functional 
behavior analysis based on formal methods is a qualitative analysis that can detect logical errors, leads to a better consistency, and focuses on the logic of models.

\section{Analysis literature review}

In order to analyze enterprise models, we performed a Systematic Literature Review (SLR), for identifying analysis methods suitable with the needs of enterprises. Based on Lankhorst (2005) classification, we have selected references, which propose approaches suitable with the quantitative and functional analysis dimensions. The method of the SLR includes research questions, search process, and inclusion exclusion criteria (Kitchenham et al. 2009, 2010; Lisboa et al. 2010). The research questions addressed in this work are:

- RQ1. What enterprise automated analyses have been addressed? Enterprise automated analysis are performed based on models, but models are created in different modeling languages. We are interested in finding automated analysis addressed by different authors in the enterprise context. In order to address RQ1, we identified automated analyses published in journals, conferences, and books.

- RQ2. What enterprise automated analyses are proposed by enterprise frameworks? Enterprise frameworks provide elements such as definitions, methods, guidelines, techniques. We consider that based on these elements, it is possible to assert some automated analysis that have not been addressed.

- RQ3. What analyses of models and graphs have application in the enterprise context? Since automated analysis are based on models, we are interested in including graph analyses (e.g., topological analysis) and models analyses (e.g., conformance analysis) in order to discover enterprise insights based on the characteristics of the model.

The search process was a manual search of conference proceedings, journals, and books that include studies regarding enterprise, graphs, or models analysis, regardless of impact factors and other bibliometrics. This search was done by consulting scientific literature databases such as IEEE Explore, ACM Digital Library, Springer, and Oxford Journals, among others; however, we also searched specific enterprise modeling journals that includes works about enterprise analysis. Selected conferences proceedings, journals, books, and frameworks are presented in Table 1. Selected conference proceedings have program committees and program chairs well known in the field. In addition, the search process included enterprise frameworks which propose enterprise analyses which might be automated. Ultimately, among those frameworks we only included TOGAF because it compiles elements included in previous models and because it is, among the most popular frameworks, the one that delves the most into methodological aspects.

Once literature in enterprise analysis was collected, we had to asses whether or not it was relevant. To achieve this, we defined inclusion and exclusion criteria. The inclusion criteria were:

- Peer reviewed articles or books, which propose enterprise analysis techniques that can be classified in the quantitative or functional dimension.

- Peer reviewed articles or books, which propose graph or model analysis. 
Table 1 Selected journals, books, and conference proceedings

\begin{tabular}{|c|c|}
\hline Source & Type \\
\hline ACM/IEEE International Conference on Software Engineering & Conference Proceedings \\
\hline ACM/IEEE International Symposium on Microarchitecture & Conference Proceedings \\
\hline Enterprise Modelling and Information Systems Architectures & Journal \\
\hline European Conference on Software Architecture & Conference Proceedings \\
\hline Graph theory & Book \\
\hline High availability and disaster recovery: concepts, design, implementation & Book \\
\hline IEEE International Enterprise Distributed Object Computing Conference & Conference Proceedings \\
\hline IEEE Workshop on Software Development Governance & Conference Proceedings \\
\hline International CMG Conference & Conference Proceedings \\
\hline Interoperability of Enterprise Software and Applications & Journal \\
\hline IT professional & Journal \\
\hline Journal of Information, Law \& Technology & Journal \\
\hline Journal of Object Technology & Journal \\
\hline Long Range Planning & Journal \\
\hline Model-Driven Engineering Languages and Systems & Book \\
\hline Network design for IP convergence & Book \\
\hline Sloan management review & Journal \\
\hline Software quality attributes and trade-offs & Book \\
\hline TOGAF Version 9.1 & Framework \\
\hline
\end{tabular}

- Enterprise frameworks that provide enterprise analyses.

The exclusion criteria were:

- Studies that propose enterprise analysis techniques focused on simulation, animation, or another technique that illustrate dynamic behavior of the enterprise.

Based on the search process and on the inclusion and exclusion criteria, a set of references were selected. Selected references are presented below grouped by: quantitative dimension, functional dimension, or both dimensions (i.e., references that provide analyses applicable in quantitative and functional dimensions).

Regarding quantitative dimension, Iacob and Jonkers (2006) present and approach, for the quantification of performance of enterprise architectures applicable in the business, application, and infrastructure layers of ArchiMate. Davenport and Short (1990) propose a five-step approach for redesigning processes with IT in order to optimize the efficiency of the processes in enterprises. Armistead et al. (1999) expose a strategic view of business process management, useful for measuring business process effectiveness and human resources influence in business processes. Akkary and Driscoll (1998) present an architecture that improves instruction supply based on infrastructure resources such as memory and processor. Menascé and Bennani (2006) present analytical models for a wide range of multithreaded software server architectures. Di Penta et al. (2010) motivate the problem of analyzing the evolution of licensing statements and propose an approach to automatically track the licensing evolution of systems, identifying changes in licenses and copyright years. Somasundaram and Shrivastava (2009) explain information storage techniques, for managing and analysing storage volumetrics. Quartel et al. 
(2010) present a valuation approach to determine the cost and contribution of IT to the business. Berander et al. (2005) present management-oriented quality attributes models, which allows analysing the relation between quality attributes in IT elements. These works contribute with analyses that provide results based on specific indicators (e.g., availability, performance, optimization).

Regarding functional dimension, Sunkle et al. (2013) propose an approach to demonstrate how to perform impact of change analyses in the EA context based on ontologies. In The Open Group (2012), ArchiMate is presented by The Open Group as and EA modeling language, where structure and behavior is defined. Guadamuz (2001) explains Habeas Data as a legal tool for data protection providing elements to analyze the way in which IT comply data security. Lam (2002) presents an approach to business continuity planning (BCP) in order to avoid falls based on a practical value in a wide range of ITrelated organizations. Angelov et al. (2009) study several reference architectures in order to investigate the contextual factors that influence the success of a reference architecture. Gómez et al. (2014) propose an approach for managing model and metamodel conformance, for the EA context making the distinction between linguistic and ontological conformance. In The Open Group (2011), TOGAF is presented by The Open Group as and EA standar framework. Bollobás (1982) presents the graph theory that is suitable for topology analyses. Kofman et al. (2009) present a governance solution for specifying governance capabilities, decision rights and responsibilities. Fischer et al. (2007) propose a federal approach for EA maintenance, which involves the participation of business actors and roles. These works provide analysis methods, for determining certain characteristics of the architecture (e.g., alignment, coherence) or the model (Graph structure, conformance).

In addition, there are references that include analysis in both, the quantitative and the functional dimensions. Donoso (2009) addresses network design providing strategies for managing and analyzing network resources and volumetric. Schmidt (2006) presents solutions for planning and implementing successfully high availability and disaster recovery providing needed server requirements to support business operation. Florez et al. (2014) present a proposal for analysing enterprise models based on ArchiMate modeling language, illustrating availability and requirements of infrastructure and application layers.

The literature review allowed us not only to identify analysis methods, but to understand the diversity of enterprise analyses. This diversity helped us to classify analysis methods in a more specialized category than the analysis dimension.

\section{A catalog of automated analysis methods}

There are a lot of enterprise analyses that can be performed automatically based on an enterprise model. In order to propose a catalog of alutomated analysis methods, we have made the following activities: (1) literature review (presented in the previous section) regarding analysis; (2) identification of analysis methods based on the literature review; (3) classification of identified analysis methods by analysis dimension (quantitative and functional); (4) classification of identified analysis methods by analysis type; (5) characterization of analysis methods; (6) unified documentation of each analysis method; (7) development of the algorithms, for each analysis method; (8) implementation of 
the analysis methods. The catalog then contains valuable information of each analysis method that can be used by analysts and modelers as a guide, when they are interested in creating enterprise models for analyzing the enterprise. On the one hand, when the analyst wants to analyze the enterprise, it is important to know what kinds of analyses are going to be performed. Then, the analyst can use the catalog in order to identify which automated analysis methods provide proper results. On the other hand, the cata$\log$ can be used by the modeler to know which information is mandatory, for performing desired analysis methods.

Based on the characteristics of the identified analysis methods, we proposed the following 16 analysis types: Performance (Pe): measures the ability of the system, for complying its activities based on a desired parameter (e.g., response time); Optimization (Op): estimates the efficiency and effectiveness of the system processes; Impact of Change (IoC): determines the consequences of modifying the system; Capacity Planning (CP): estimates needed resources, for achieving desired goals; Cost (Cos): establishes costs of the business; Availability (Av): estimates the percentage of time that the system is working correctly; Trade-Off (TO): measures the relation between quality attributes; Human Resources (HR): provides different kinds of results regarding actors or roles; Alignment (Al): determines if elements of different layers of the system are correctly adjusted; Coherence (Coh): verifies that all elements of the system have proper related elements; Correctness (Cor): corroborates that the system complies the requirements; Conformance (Con): finds out errors regarding the relation between the model and the metamodel of the modeling language; Gap $(\mathrm{Ga})$ : presents the differences between AS-IS and TO-BE models; Graph Structure (GS): checks the topology characteristics of the model; Count ( $\mathrm{Cou}$ ): calculates the amount of elements or relations of the model based on a given parameter; and Process (Pr): finds out specific relations between business processes and another desired elements of the model. The 16 analysis types were proposed in order to classify the analysis methods in a more specific way than just the analysis dimension. The types were taken based on the purpose of the identified analysis methods.

We have identified 78 analysis methods as result of the SLR. These methods were selected because they can be addressed in the enterprise context and they can be implemented to be performed automatically. Table 2 presents the distribution of the references of the literature review made in this work, sorting the references by dimension and type.

Each analysis method in the catalog is classified by dimension (e.g., quantitative or functional), type of the analysis (e.g., performance, cost, availability), and TOGAF Architecture Domain that can be Business Architecture (BA), Data Architecture (DA), Application Architecture (AA), and Technology Architecture (TA). In addition, based on ArchiMate, each analysis method has a unified and well-defined documentation. The documentation of analysis methods provides the required information for understanding the purpose, requirements, mode of use, and results. The documentation also aims to reuse analysis methods due to they are applicable to any ArchiMate model. The documentation contains: (1) id, which is a code for identifying the analysis method that includes three letters indicating the dimension, type, and a consecutive number of three digits (e.g., QAV004 indicating that the analysis method is the fourth that belongs 
Table 2 Distribution of references

\begin{tabular}{lll}
\hline Dimension & Type & References \\
\hline Quantitative & Pe & lacob and Jonkers (2006) \\
& Op & Armistead et al. (1999) and Davenport and Short (1990) \\
loc & Akkary and Driscoll (1998), Donoso (2009), Menascé and Bennani (2006) and Di Penta et al. \\
& (2010) \\
CP & Donoso (2009), Schmidt (2006) and Somasundaram and Shrivastava (2009) \\
Cos & Quartel et al. (2010) \\
Av & Florez et al. (2014) and Schmidt (2006) \\
TO & Berander et al. (2005) \\
HR & Armistead et al. (1999) and Davenport and Short (1990) \\
IoC & Sunkle et al. (2013) \\
Al & The Open Group (2012) \\
Coh & The Open Group (2012) \\
Cor & Donoso (2009), Florez et al. (2014), Guadamuz (2001), Lam (2002), Schmidt (2006) \\
Con & and The Open Group (2012) \\
Ga & The Open Group (2011) \\
GS & Bollobás (1982) and The Open Group (2012) \\
Cou & The Open Group (2012) \\
Pr & Angelov et al. (2009) and Kofman et al. (2009) \\
HR & Fischer et al. (2007)
\end{tabular}

to the dimension quantitative and the type availability); (2) name; (3) ArchiMate layer, which indicates the layer involved in the analysis method (e.g., Business, Application, Infrastructure, Motivation); (4) description; (5) elements, which informs all ArchiMate element types that are used in the analysis method (e.g., Bus iness Process, ApplicationComponent, Device); (6) relations, which informs the required ArchiMate relations between elements used in the analysis method (e.g., UsedBy, Realization, Flow); (7) required attributes, which specifies the involved attributes for running the desired analysis method; (8) algorithm, which presents the procedure for extracting information from the model and calculating the correspondent result; and (9) output, which informs the kinds of results that the analysis method provides (e.g., model enriched, report). Table 3 presents the catalog with the quantitative dimension, while Table 4 presents the catalog with the functional dimension.

We also have classified all analysis methods in the Zachman Framework for Enterprise Architecture (Zachman 2006) in order to identify the audience perspectives and classification names of each method. Table 5 presents the resulting classification. This classification was done by identifying the analysis methods that satisfies each intersection of the framework, where intersections combine the primitive interrogatives of the framework (What, How, When, Who, Where, and Why) with the transformations also identified in the framework (Identification (Scope Context), Definition (Business Concepts), Representation (System Logic), Specification (Technology Physics), Configuration (Tool Components), and Implementation (Operation Instances)). For instance, the method QIC002: Modify (increase/Decrease) Network resources was included in two intersections of the framework: the first one is the intersection of the primitive Where and the transformation Specification (Technology Physics), and the second one is the intersection of the 
Table 3 Catalog of quantitative automated analysis methods

\begin{tabular}{|c|c|c|c|}
\hline Type & Id & Domain & Name \\
\hline \multirow[t]{3}{*}{$\mathrm{Pe}$} & QPR001 & TA & Infrastructure services workload (lacob and Jonkers 2006) \\
\hline & QPRO02 & AA & Application services processing and response time (lacob and Jonkers 2006) \\
\hline & QPR003 & AA & Application services utilization (lacob and Jonkers 2006) \\
\hline \multirow[t]{2}{*}{ Op } & QOP001 & $B A, D A, A A$ & $\begin{array}{l}\text { Estimate process efficiency based on resources usage (Davenport and Short } \\
\text { 1990) }\end{array}$ \\
\hline & QOP002 & BA & Estimate process effectiveness (Davenport and Short 1990) \\
\hline \multirow[t]{4}{*}{ loC } & QIC001 & TA & Modify (increase/decrease) Infrastructure resources (Akkary and Driscoll 1998) \\
\hline & QIC002 & TA & Modify (increase/decrease) Network resources (Donoso 2009) \\
\hline & QIC003 & $\mathrm{AA}, \mathrm{TA}$ & $\begin{array}{l}\text { Modify (increase/decrease) threads of a service / application (concurrency) } \\
\text { (Menascé and Bennani 2006) }\end{array}$ \\
\hline & QIC004 & AA & $\begin{array}{l}\text { Modify (increase/decrease) quantity of users, license implications (Di Penta } \\
\text { et al. 2010) }\end{array}$ \\
\hline \multirow[t]{3}{*}{$C P$} & QCP001 & $B A, D A, A A, T A$ & $\begin{array}{l}\text { Estimate overall solution architecture storage volumetric (Somasundaram and } \\
\text { Shrivastava 2009) }\end{array}$ \\
\hline & QCP002 & $B A, D A, A A, T A$ & Estimate overall solution architecture network volumetric (Donoso 2009) \\
\hline & QCP003 & $B A, D A, A A, T A$ & Estimate number of servers required to support operation (Schmidt 2006) \\
\hline \multirow[t]{4}{*}{ Cos } & QCT001 & $B A, D A, A A, T A$ & Overall architecture Cost (Quartel et al. 2010) \\
\hline & QCT002 & $B A, D A, A A, T A$ & Overall architecture Cost/Benefit (Quartel et al. 2010) \\
\hline & QCT003 & $B A, D A, A A, T A$ & Overall architecture ROI (Quartel et al. 2010) \\
\hline & QCT004 & $B A, D A, A A, T A$ & Overall architecture required portfolio (Quartel et al. 2010) \\
\hline \multirow[t]{4}{*}{ Av } & QAV001 & $B A, D A, A A, T A$ & Estimate overall architecture availability (Schmidt 2006) \\
\hline & QAV002 & $B A, D A, A A, T A$ & Estimate overall architecture RTO (Schmidt 2006) \\
\hline & QAV003 & $B A, D A, A A, T A$ & Estimate overall architecture RPO (Schmidt 2006) \\
\hline & QAV004 & AA & Application component availability (Florez et al. 2014) \\
\hline \multirow[t]{10}{*}{ TO } & QTO001 & AA & Application service Performance versus Flexibility (Berander et al. 2005) \\
\hline & QTO002 & AA & Application service Performance versus Security (Berander et al. 2005) \\
\hline & QTO003 & AA & Application interface Performance versus Flexibility (Berander et al. 2005) \\
\hline & QTO004 & AA & Application interface Performance versus Security (Berander et al. 2005) \\
\hline & QTO005 & AA & Application component Performance versus Flexibility (Berander et al. 2005) \\
\hline & QTO006 & AA & Application component Performance versus Security (Berander et al. 2005) \\
\hline & QTO007 & DA & Data Access Performance versus Flexibility (Berander et al. 2005) \\
\hline & QTO008 & DA & Data Access Performance versus Security (Berander et al. 2005) \\
\hline & QTO009 & $B A, D A, A A, T A$ & Overall process Performance versus Flexibility (Berander et al. 2005) \\
\hline & QTO010 & $B A, D A, A A, T A$ & Overall process Performance versus Security (Berander et al. 2005) \\
\hline \multirow[t]{5}{*}{ HR } & QHR001 & BA & Human Resource workload at business process level (Armistead et al. 1999) \\
\hline & QHR002 & BA & $\begin{array}{l}\text { Human Resource capacity requirements at business process level (Armistead } \\
\text { et al. 1999) }\end{array}$ \\
\hline & QHR003 & BA & Business processes participants (Armistead et al. 1999) \\
\hline & QHRO04 & BA & $\begin{array}{l}\text { Roles by business process or function that have only one accountable actor } \\
\text { (Davenport and Short 1990) }\end{array}$ \\
\hline & QHR005 & BA & Human resources capacity planning (Armistead et al. 1999) \\
\hline
\end{tabular}

primitive Where and the transformation Configuration (Tool Components). The method was placed in these intersections because (a) it is intended to adjust the amount of infrastructure resources required for the right operation of IT systems in an organization and (b) the cells defines the IT distribution specification and configuration.

In this paper, we just illustrate the quantitative analysis methods: QHR003 and QAV004 and the functional analysis methods: FIC001 and FCO009. However, all information of the catalog is available in http://catalog.virtual.uniandes.edu.co. We have 


\section{Table 4 Catalog of functional automated analysis methods}

\begin{tabular}{|c|c|c|c|}
\hline Type & Id & Domain & Name \\
\hline \multirow[t]{2}{*}{ loC } & FIC001 & $\mathrm{BA}, \mathrm{DA}, \mathrm{AA}, \mathrm{TA}$ & Impact of removing elements (Sunkle et al. 2013) \\
\hline & $\mathrm{FICO02}$ & $B A, D A, A A, T A$ & Impact of removing a relation between two elements (Sunkle et al. 2013) \\
\hline \multirow[t]{3}{*}{$\mathrm{Al}$} & FAG001 & $B A, A A$ & Business-Application Alignment (The Open Group 2012) \\
\hline & FAG002 & $B A, T A$ & Business-Technology Alignment (The Open Group 2012) \\
\hline & FAG003 & $\mathrm{AA}, \mathrm{TA}$ & Application-Technology Alignment (The Open Group 2012) \\
\hline \multirow[t]{4}{*}{ Coh } & $\mathrm{FCH} 001$ & BA & $\begin{array}{l}\text { Every business active structure has at least one direct/derived assignment (The } \\
\text { Open Group 2012) }\end{array}$ \\
\hline & $\mathrm{FCH} 002$ & BA & $\begin{array}{l}\text { Every business process realizes as least one business service (The Open Group } \\
\text { 2012) }\end{array}$ \\
\hline & $\mathrm{FCH} 003$ & $\mathrm{AA}, \mathrm{TA}$ & $\begin{array}{l}\text { Every application component uses infrastructure service, node, or device (The } \\
\text { Open Group 2012) }\end{array}$ \\
\hline & $\mathrm{FCHOO4}$ & $B A, A A$ & $\begin{array}{l}\text { Every application service is used at least in one business process (The Open } \\
\text { Group 2012) }\end{array}$ \\
\hline \multirow[t]{9}{*}{ Cor } & FCO001 & DA & Data security compliance at transport level (Guadamuz 2001) \\
\hline & FCO002 & DA & Data security compliance at persistence level (Guadamuz 2001) \\
\hline & FCO003 & BA & Business layer single point of fail (Lam 2002) \\
\hline & FCO004 & AA & Application layer single point of fail (Schmidt 2006) \\
\hline & FCO005 & TA & Technology layer single point of fail (Schmidt 2006) \\
\hline & FCO006 & $B A, D A, A A, T A$ & Overall architecture single point of fail (Schmidt 2006) \\
\hline & FCO007 & AA & $\begin{array}{l}\text { Integration protocols compatibility at application service level (The Open } \\
\text { Group 2012) }\end{array}$ \\
\hline & FCO008 & TA & $\begin{array}{l}\text { Communication and transport protocols compatibility at technology level } \\
\text { (Donoso 2009) }\end{array}$ \\
\hline & FCO009 & TA & Requirement compliance at infrastructure level (Florez et al. 2014) \\
\hline \multirow[t]{5}{*}{ Con } & FCF001 & $B A, D A, A A, T A$ & Metamodel conformance (Gómez et al. 2014) \\
\hline & FCF002 & DA & $\begin{array}{l}\text { Reference architecture conformance at Data/Information level (Angelov et al. } \\
\text { 2009) }\end{array}$ \\
\hline & FCF003 & AA & Reference architecture conformance at Application level (Angelov et al. 2009) \\
\hline & FCF004 & AA & $\begin{array}{l}\text { Reference architecture conformance at Application Integration level (Angelov } \\
\text { et al. 2009) }\end{array}$ \\
\hline & FCF005 & TA & Reference architecture conformance at Technology level (Angelov et al. 2009) \\
\hline \multirow[t]{5}{*}{ Ga } & FGP001 & $\mathrm{BA}$ & Business process Gap Analysis (The Open Group 2011) \\
\hline & FGP002 & DA & Data/Information Architecture GAP Analysis (The Open Group 2011) \\
\hline & FGP003 & AA & Application Architecture GAP Analysis (The Open Group 2011) \\
\hline & FGP004 & AA & Application-Integration Architecture GAP Analysis (The Open Group 2011) \\
\hline & FGP005 & TA & Technology Architecture GAP Analysis (The Open Group 2011) \\
\hline \multirow[t]{6}{*}{ GS } & FGR001 & $B A, D A, A A, T A$ & Circular reference (Bollobás 1982) \\
\hline & FGR002 & $B A, D A, A A, T A$ & Derived associations (The Open Group 2012) \\
\hline & FGR003 & BA, DA, AA, TA & Element depth by typed relations (The Open Group 2012) \\
\hline & FGR004 & $B A, D A, A A, T A$ & Minimum spanning tree (Bollobás 1982) \\
\hline & FGR005 & $B A, D A, A A, T A$ & Shortest path by typed relations (Bollobás 1982) \\
\hline & FGR006 & $\mathrm{BA}, \mathrm{DA}, \mathrm{AA}, \mathrm{TA}$ & Element dependency (Bollobás 1982) \\
\hline \multirow[t]{2}{*}{$\mathrm{Cou}$} & FCN001 & $\mathrm{BA}, \mathrm{DA}, \mathrm{AA}, \mathrm{TA}$ & Counting of elements by types (The Open Group 2012) \\
\hline & FCNO02 & $B A, D A, A A, T A$ & Counting of relationships by types (The Open Group 2012) \\
\hline \multirow[t]{3}{*}{$\operatorname{Pr}$} & FPR001 & $\mathrm{DA}, \mathrm{AA}$ & Data/Information versus Application (Angelov et al. 2009) \\
\hline & FPR002 & BA, DA & Data/Information versus Process (Angelov et al. 2009) \\
\hline & FPR003 & BA & Process responsibility assignment (Kofman et al. 2009) \\
\hline \multirow[t]{3}{*}{ HR } & FHRO01 & BA & Business layer passive elements RACI matrix (Fischer et al. 2007) \\
\hline & FHRO02 & AA & Application layer passive elements RACI matrix (Fischer et al. 2007) \\
\hline & FHROO3 & TA & Technology layer passive elements RACI matrix (Fischer et al. 2007) \\
\hline
\end{tabular}


Table 5 Analysis methods classification in the Zachman Framework

\begin{tabular}{|c|c|c|c|c|c|c|c|}
\hline & What & How & Where & Who & When & Why & \\
\hline Executive & $\begin{array}{l}\text { QCT001 } \\
\text { QCT002 }\end{array}$ & $\begin{array}{l}\text { QCT003 } \\
\text { QCT004 }\end{array}$ & $\begin{array}{l}\text { FCO003 } \\
\text { FCO006 }\end{array}$ & QHR005 & $\begin{array}{l}\text { QTO009 } \\
\text { FGP001 }\end{array}$ & QTO010 & $\begin{array}{l}\text { Scope } \\
\text { Context }\end{array}$ \\
\hline $\begin{array}{l}\text { Business } \\
\text { manage- } \\
\text { ment }\end{array}$ & $\begin{array}{l}\text { QAV001 } \\
\text { FHC001 } \\
\text { FCF002 } \\
\text { FPR001 }\end{array}$ & $\begin{array}{l}\text { QAV002 } \\
\text { QAV003 } \\
\text { FHC002 } \\
\text { FPR002 }\end{array}$ & $\begin{array}{l}\text { FAG001 } \\
\text { FAG002 } \\
\text { FCH004 } \\
\text { FCO003 }\end{array}$ & $\begin{array}{l}\text { QOP002 } \\
\text { QHR001 } \\
\text { QHR003 } \\
\text { QHR004 } \\
\text { FHR001 }\end{array}$ & $\begin{array}{l}\text { QOP001 } \\
\text { QTO007 } \\
\text { QTO009 }\end{array}$ & $\begin{array}{l}\text { QTO008 } \\
\text { QTO010 } \\
\text { QHR002 } \\
\text { FPR003 }\end{array}$ & $\begin{array}{l}\text { Business } \\
\text { Concepts }\end{array}$ \\
\hline Architect & $\begin{array}{l}\text { QCP003 } \\
\text { QAV001 } \\
\text { FIC001 } \\
\text { FIC002 } \\
\text { FCF004 } \\
\text { FGR00* }\end{array}$ & $\begin{array}{l}\text { QCP001 } \\
\text { QAV002 } \\
\text { QAV003 }\end{array}$ & $\begin{array}{l}\text { QCP002 } \\
\text { FAG001 } \\
\text { FAG003 } \\
\text { FCO004 }\end{array}$ & $\begin{array}{l}\text { QHR001 } \\
\text { FCO001 } \\
\text { FCO002 } \\
\text { FHR002 }\end{array}$ & FGP002 & QHROO2 & $\begin{array}{l}\text { System } \\
\text { Logic }\end{array}$ \\
\hline Engineer & $\begin{array}{l}\text { QPR001 } \\
\text { QAV004 } \\
\text { FCF003 } \\
\text { FCF005 } \\
\text { FCN001 } \\
\text { FCN002 } \\
\text { FGR00* }\end{array}$ & $\begin{array}{l}\text { QPRO03 } \\
\text { QIC001 }\end{array}$ & $\begin{array}{l}\text { QICO02 } \\
\text { FAG002 } \\
\text { FAG003 } \\
\text { FCH003 } \\
\text { FCO005 } \\
\text { FCO007 }\end{array}$ & $\begin{array}{l}\text { QIC004 } \\
\text { FHRO03 }\end{array}$ & $\begin{array}{l}\text { QPR002 } \\
\text { QTO001 } \\
\text { QTO003 } \\
\text { QTP005 } \\
\text { FGP003 } \\
\text { FGP004 }\end{array}$ & $\begin{array}{l}\text { QICO03 } \\
\text { QTO002 } \\
\text { QTO004 } \\
\text { QTO006 } \\
\text { FCO009 }\end{array}$ & Tech. Physics \\
\hline Technician & $\begin{array}{l}\text { QPR001 } \\
\text { QAV004 }\end{array}$ & $\begin{array}{l}\text { QPR003 } \\
\text { QIC001 }\end{array}$ & $\begin{array}{l}\text { QIC002 } \\
\text { FCO008 }\end{array}$ & $\begin{array}{l}\text { QIC004 } \\
\text { FHR003 }\end{array}$ & $\begin{array}{l}\text { QPRO02 } \\
\text { FGP005 }\end{array}$ & $\begin{array}{l}\text { QIC003 } \\
\text { FCO009 }\end{array}$ & Tool Comp. \\
\hline \multirow[t]{2}{*}{ Enterprise } & $\begin{array}{l}\text { FCF001 } \\
\text { QCT001 } \\
\text { QCT002 }\end{array}$ & $\begin{array}{l}\text { QCT003 } \\
\text { QCT004 }\end{array}$ & FCO006 & QHR001 & $\begin{array}{l}\text { FGP001 } \\
\text { QTO009 }\end{array}$ & QTO010 & $\begin{array}{l}\text { Op. } \\
\text { Instances }\end{array}$ \\
\hline & Invent. Sets & Process Flows & $\begin{array}{l}\text { Distrib. Net- } \\
\text { work }\end{array}$ & $\begin{array}{l}\text { Respons. } \\
\text { Assignm. }\end{array}$ & \multicolumn{3}{|c|}{$\begin{array}{l}\text { Timing Cycles Motivat. } \\
\text { Intention }\end{array}$} \\
\hline
\end{tabular}

* Analysis methods FGR001, FGR002, FGR003, FGR004, FGR005, and FGR006

selected these analysis methods in order to illustrate the following situations: (a) results that require specific attributes and enrich the model including new attributes; (b) results that provide facts, but require specific attributes; and (c) results that require attributes and enrich the model including new relations. All analysis methods have a unified documentation shown in the illustrated methods.

\section{Quantitative analysis method: business processes participants}

Table 6 presents the documentation of the analysis method QHR003: Business Processes Participants, which enumerates the business actors and business roles associated with all business processes. This association can be direct or indirect. On the one hand, actors or roles are directly associated with one process, when there is an Assignment relation from the actor or role to the process. On the other hand, actors or roles are indirectly associated with one process, when there are business interactions, business collaborations, or business functions between the actors or roles and the process. This method illustrates (a) the need of the correspondent relations between business elements and (b) the reporting of the analysis method results with specific details.

Algorithm 1 calculates the results of the analysis method QHR003, where $B P=B u s i$ nessProcess, $B A=$ BusinessActor, $B R=$ BusinessRole, $B C=$ BusinessCollaboration, and $B I=$ BusinessInteraction. The algorithm iterates all business processes. For each business process, the algorithm gets the relations and verifies whether each relation targets one business actor or business role. If true, the business actor or business role is collected; 
Table 6 Automated analysis method: QHROO3

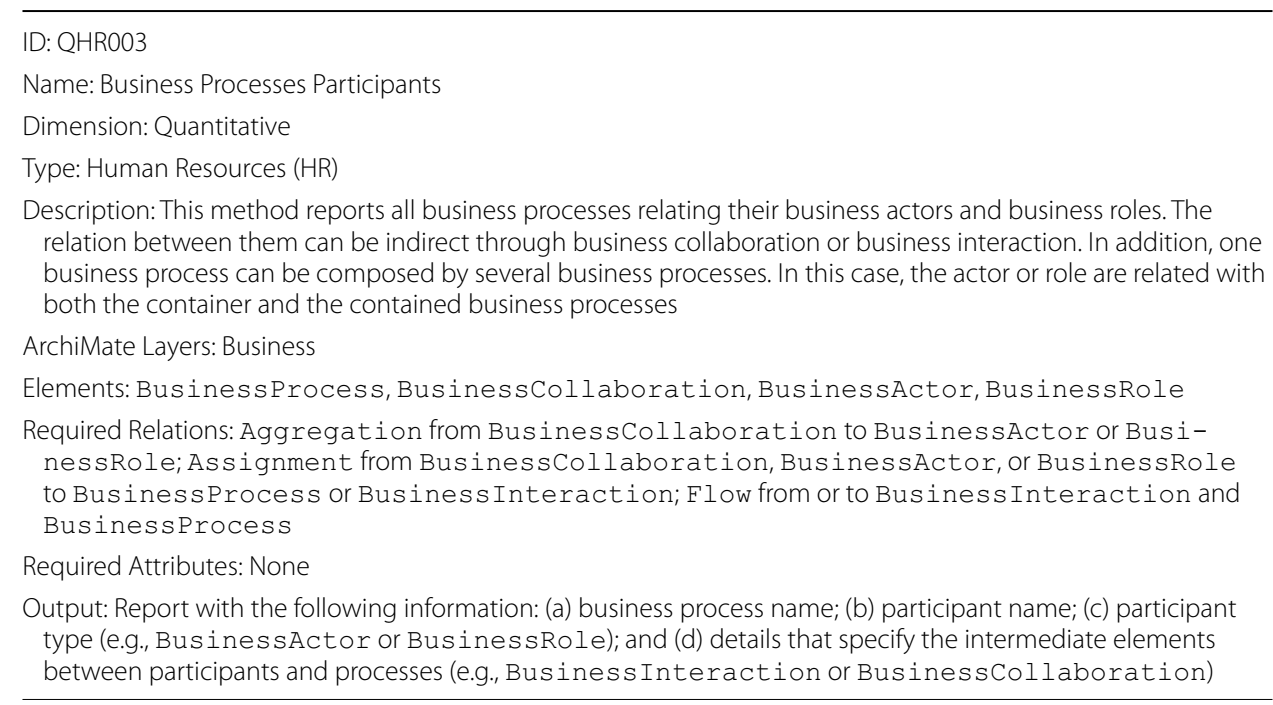

however, if false, the algorithm verifies whether the consulted relation targets one business collaboration or business interaction. If true, the algorithm gets the relations of the gathered business collaboration or business interaction and verifies whether each relations targets one business actor or business role, for collecting them as well.

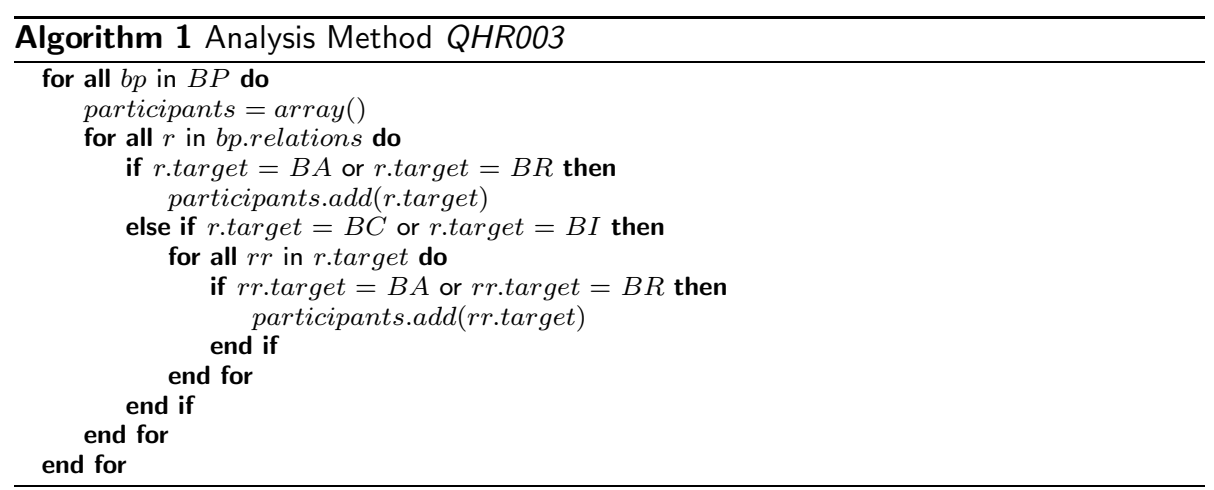

Figure 1 presents one fragment of the business process view of the enterprise model of the publisher scenario. It includes several business processes, where some of them are related with other business processes through a Composition relation (i.e., container) or Flow relation. The model also includes business interactions related with business processes through $\mathrm{Fl}$ ow relation as well. Business collaborations are related with business processes and business interactions trough Assignment relations. Finally, business actors and business roles are related with business processes, business interactions, or business collaborations through Assignment relations. The analysis method Business Process Participants has been run using this model.

Figure 2 presents one part of the results of the analysis method. The result is a report that includes all business processes with the correspondent associated business actors or business roles. In addition, the report includes details when the relation between 


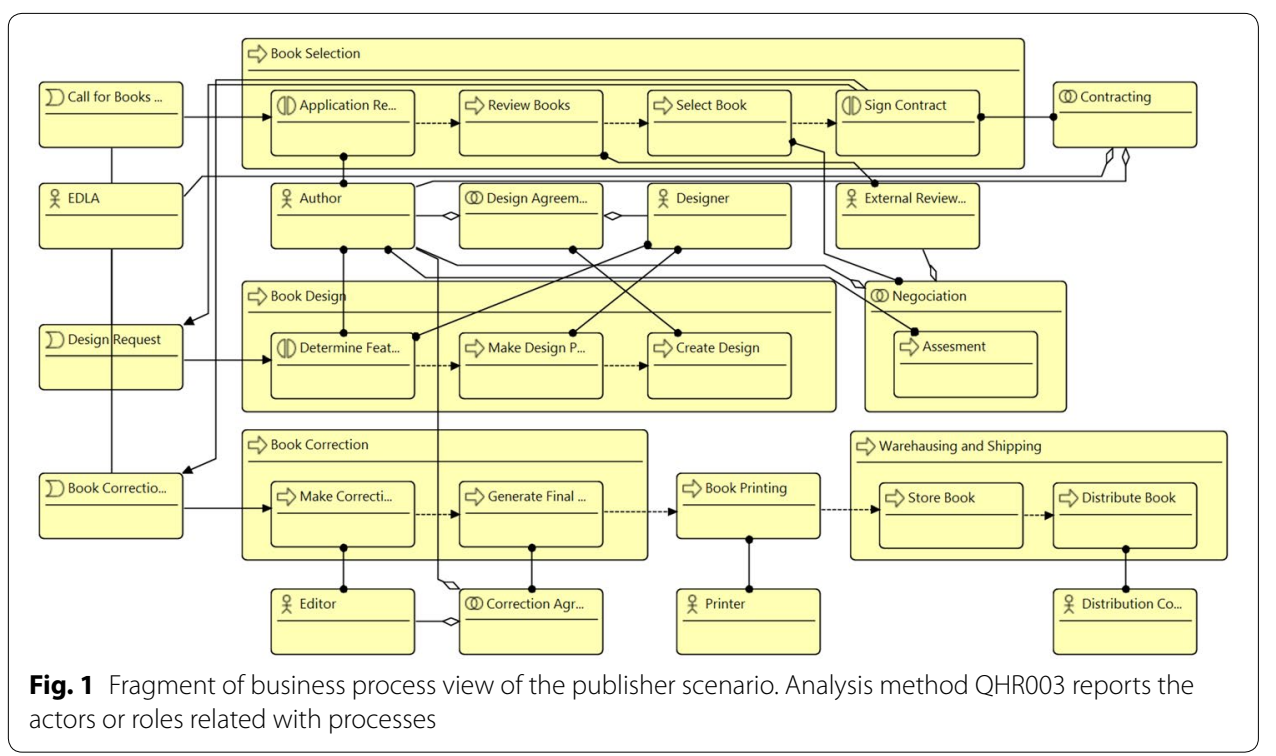

the business process and the business actor or business role is indirect; thus, the details informs the business elements involved in the relation.

\section{Quantitative analysis method: application component availability}

Table 7 presents the quantitative automated analysis method QAV004: Application Component Availability. This analysis method is intended to calculate the availability of all application components based on the related infrastructure elements. This method illustrates the need of the required attribute availability in Device, the reporting of the analysis method results, and the enrichment of the model with new attributes (availability in SystemSoftware, InfrastructureService, and ApplicationComponent).

Algorithm 2 calculates the results of the analysis method QAV004, where $I E=$ Infrastructure Element such as Device, SystemSoftware, or InfrastructureService;

\begin{tabular}{|c|c|c|c|c|}
\hline \multicolumn{5}{|c|}{ 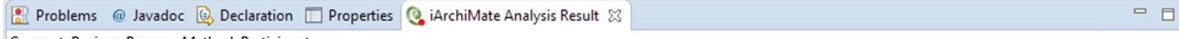 } \\
\hline \multicolumn{5}{|c|}{ Concept: BusinessProcess. Method: Participants } \\
\hline \# & Business Process Name & Participant Name & Participant Type & Details \\
\hline \multirow[t]{3}{*}{1} & Agreement Creation & Legal Employee & BusinessActor & \\
\hline & & Channel & BusinessRole & \\
\hline & & Supplier & BusinessRole & \\
\hline 2 & Analysis Cubes Management & - $\quad$ & - $\quad$ & No business actors or roles found \\
\hline 3 & Application Installing & IT Employee & BusinessActor & \\
\hline 4 & Application Updating & IT Employee & BusinessActor & \\
\hline \multirow[t]{2}{*}{5} & Assesment & Author & BusinessActor & \\
\hline & & External Reviewer & BusinessActor & via Negociation (BusinessCollaboration) \\
\hline 6 & Book Commerce & - $\quad$ & - $\quad$ & No business actors or roles found \\
\hline \multirow{4}{*}{7} & Book Correction & Author & BusinessActor & \\
\hline & & Editor & BusinessActor & \\
\hline & & Editor & BusinessActor & via Generate Final Version (BusinessP rocess) via Correction Agreement (BusinessCollaborati... \\
\hline & & Editor & BusinessActor & via Make Corrections (BusinessProcess) \\
\hline \multirow[t]{6}{*}{8} & Book Design & Author & BusinessActor & \\
\hline & & Designer & BusinessActor & \\
\hline & & Designer & BusinessActor & via Create Design (BusinessProcess) via Design Agreement (BusinessCollaboration) \\
\hline & & Designer & BusinessActor & via Determine Features (BusinessInteraction) \\
\hline & & Designer & BusinessActor & via Make Design Proposal (BusinessProcess) \\
\hline & & Designer & BusinessActor & via Make Design Proposal (BusinessProcess) via Determine Features (Businessinteraction) \\
\hline 9 & Book Printing & Printer & BusinessActor & \\
\hline
\end{tabular}

Fig. 2 Analysis results. Report of analysis method: QHROO3 
Table 7 Automated analysis method: QAV004

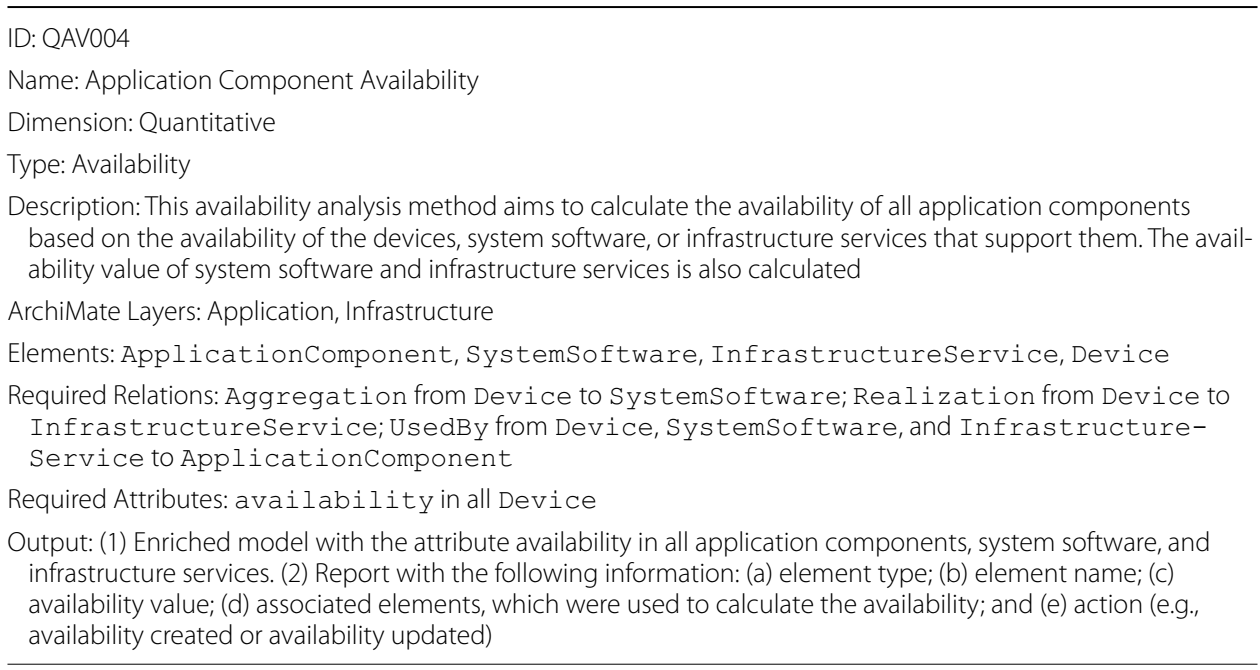

$A C=$ ApplicationComponent $A=$ Association; $C=$ Composition; $\mathrm{R}=$ Realization $;$ UB $=$ UsedBy. The algorithm iterates all infrastructure elements (i.e., devices, infrastructure services, and system software). For each infrastructure element, the algorithm gets the relations and verifies whether each relation targets one application component, infrastructure service, or system software with the correspondent relation (i.e., used by, realization, or aggregation/composition respectively). If true, the availability of the target element is multiplied by the availability of the infrastructure element.

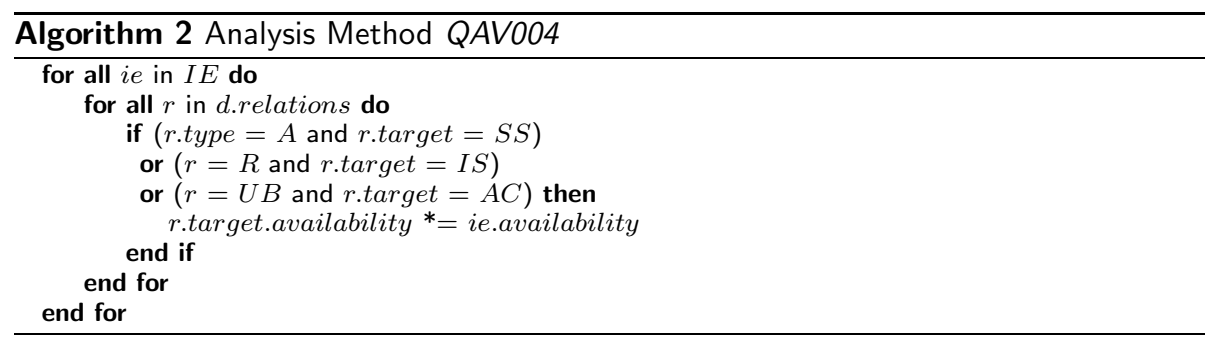

Figure 3 presents one fragment of the layered view of the enterprise model of the publisher scenario that includes elements from the application and infrastructure layers. It has the devices Windows Server and Linux Server, which aggregates some system software and realizes some infrastructure services. In addition, the model contains the application components $B I, D M S, C M S$, and $C R M$. Some infrastructure elements are used by the mentioned application components. This model has been used for running the analysis method Application Component Availability; thus, the attribute availability in the devices Windows Server and Linux Server is mandatory. In this model the attribute availability (shown in red) in all system software, infrastructure services, and application components is introduced by running the analysis method. Figure 4 reports the results of the analysis method. Before calculating the availability in the application components, the availability of system software and infrastructure services is required to be calculated. The report presents the calculated availability value for the involved 


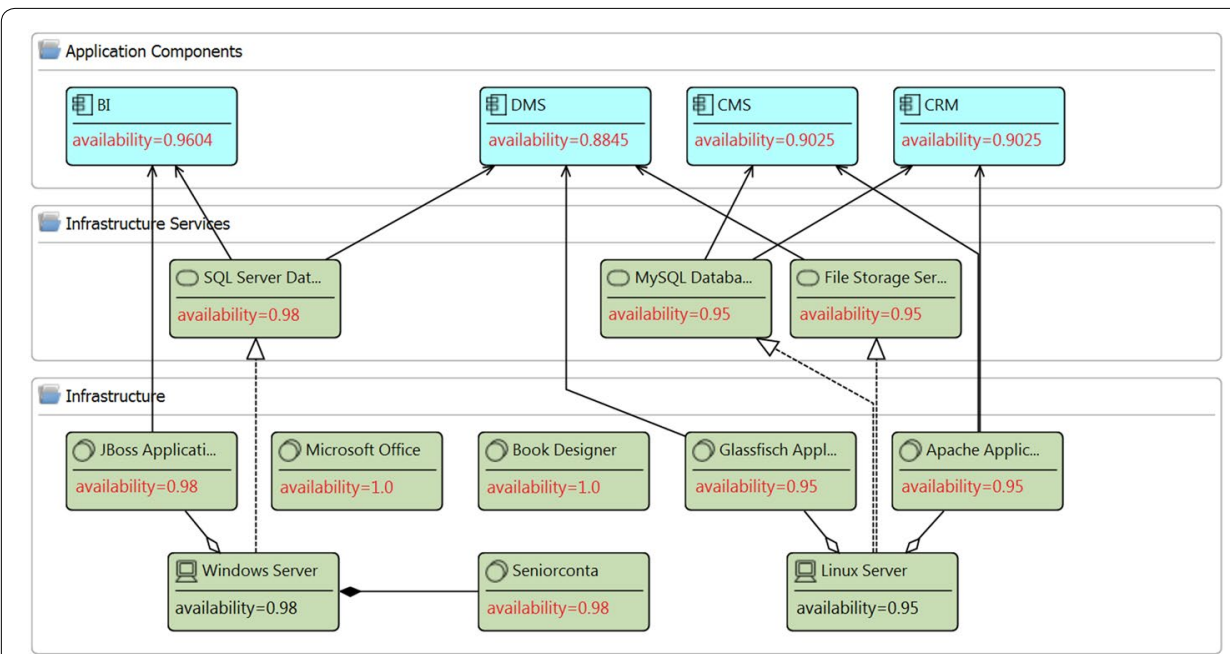

Fig. 3 Fragment of layered view of the publisher scenario. Attributes in red text have been created by the analysis method QAV004

elements. For instance, the report indicates that the availability of the ApplicationComponent CRM is 0.9025 and it was calculated based on the SystemSoftware Apache Application Server and the InfrastructureService MySQL Database Service. For this method, the ArchiMate metamodel has been extended including the attribute availability in the types Device, SystemSoftware, InfrastructureService, and ApplicationComponent.

\section{Functional analysis method: impact of removing elements}

Table 8 presents the functional automated analysis method FIC001: Impact of Removing Elements, which is intended to assess the elements impacted when one element of the model is removed. This method illustrates the need of the attribute remove in any element and the reporting of the analysis method results.

Algorithm 3 calculates the results of the analysis method FIC001, where $E=$ Elements. The algorithm iterates all elements in the model. For those elements that include the attribute remove, the algorithm collects their target elements. Later, the algorithm iterates the collected elements and collects again their targets. Thus, the algorithm

\begin{tabular}{|c|c|c|c|c|}
\hline \multicolumn{4}{|c|}{ \&Problems@ Javadoc $@$ Declaration $\square$ Properties @ i ArchiMate Analysis Result $\Sigma 3$} & \multirow[t]{2}{*}{ 口 } \\
\hline \multicolumn{4}{|c|}{ Concept: ApplicationComponent. Method: Availability } & \\
\hline Element Type & Element Name & Attribute=Value & Associated Elements & Action \\
\hline SystemSoftware & Apache Application Server & availability $=0.95$ & (1) Linux Server:availability $=0.95$. & Created \\
\hline SystemSoftware & Book Designer & availability $=1.0$ & $(0)$ & Created \\
\hline SystemSoftware & Glassfisch Application Server & availability $=0.95$ & (1) Linux Server:availability=0.95. & Created \\
\hline SystemSoftware & JBoss Application Server & availability $=0.98$ & (1) Windows Server:availability=0.98. & Created \\
\hline SystemSoftware & Microsoft Office & availability $=1.0$ & (0) & Created \\
\hline SystemSoftware & Seniorconta & availability $=0.98$ & (1) Windows Server:availability=0.98. & Created \\
\hline InfrastructureService & File Storage Senvice & availability $=0.95$ & (1) Linux Server:availability=0.95. & Created \\
\hline InfrastructureService & MYSQL Database Service & availability $=0.95$ & (1) Linux Server:availability $=0.95$. & Created \\
\hline InfrastructureService & SQL Server Database Service & availability $=0.98$ & (1) Windows Server:availability=0.98. & Created \\
\hline ApplicationComponent & BI & availability $=0.9604$ & (2) JBoss Application Server:availability=0.98. SQL Server Database Service:availability $=0.98$. & Created \\
\hline ApplicationComponent & CMS & availability $=0.9025$ & (2) Apache Application Server:availability=0.95. MySQL Database Service:availability $=0.95$. & Created \\
\hline ApplicationComponent & CRM & availability $=0.9025$ & (2) Apache Application Server:availability=0.95. MySQL Database Service:availability=0.95. & Created \\
\hline ApplicationComponent & DMS & availability $=0.8845$ & (3) Glassfisch Application Server:availability $=0.95$. File Storage Service:availability $=0.95$. SQ... & Created \\
\hline
\end{tabular}

Fig. 4 Analysis results. Report of analysis method: QAV004 
Table 8 Automated Analysis Method: FIC001

ID: FIC001
Name: Impact of Removing Elements
Dimension: Functional
Type: Impact of change
Description: This analysis method aims to assess the impact of removing one element from the model by means
of the use of the attribute remove in the element in order to simulate a logical removing process. The attrib-
ute remove is optional; then, the analysis method will analyze all elements that include the attribute remove
with the value true
ArchiMate Layers: All Layers
Elements: All elements in the model
Required Relations: Any ArchiMate relation with any source and target element
Required Attributes: remove in desired elements
Output: Report with the following information: (a) element name; (b) element type; (c) impacted elements name;
(d) impacted elements type; and (e) details that specifies the intermediate elements between the removing
element and the impacted elements

recursively can collect all direct and indirect dependent elements. The algorithm does not modify the model; thus, its output is a report that specifies all direct dependent elements and all indirect dependent elements with their correspondent trace of intermediate dependent elements.

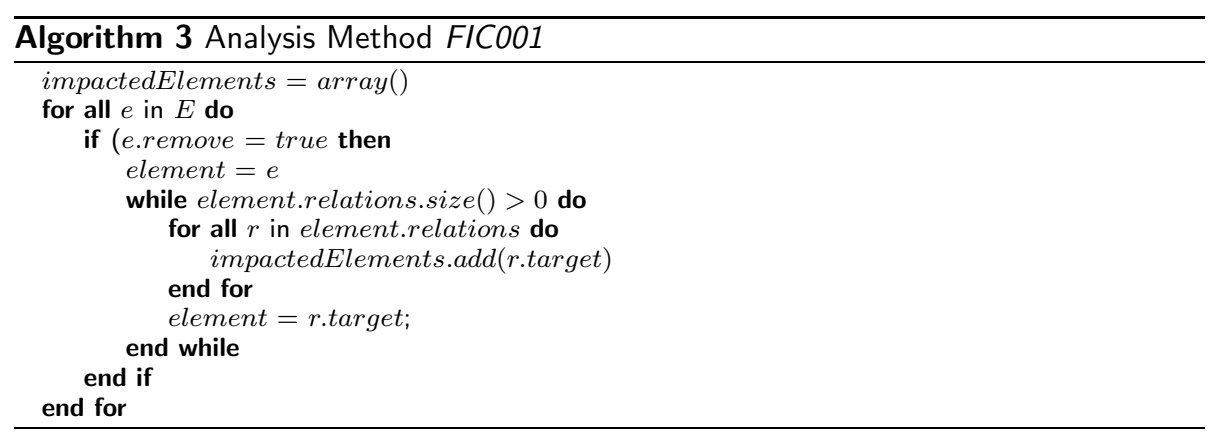

Figure 5 presents the other fragment of the layered view (presented in Fig. 3) of the enterprise model of the publisher scenario that includes elements from the business and application layers. It contains application components, which realizes several application services that are used by some business processes. The attribute remove with the value true has been introduced in the application component $C M S$ and in the application service Version Control Service. This fragment of the model has been used for running the analysis method Impact of Removing Elements. Figure 6 reports the results of the analysis method. The report presents the list of the impacted elements that depends directly or indirectly on the elements CMS or Version Control Service. When the impacted element has an indirect dependency, the report indicates the intermediate elements.

\section{Functional analysis method: requirement compliance at infrastructure level}

Table 9 presents the functional automated analysis method FCO009: Requirement Compliance at Infrastructure Level. This analysis method creates relations between requirements and IT elements, when the IT element complies the requirement condition. This 


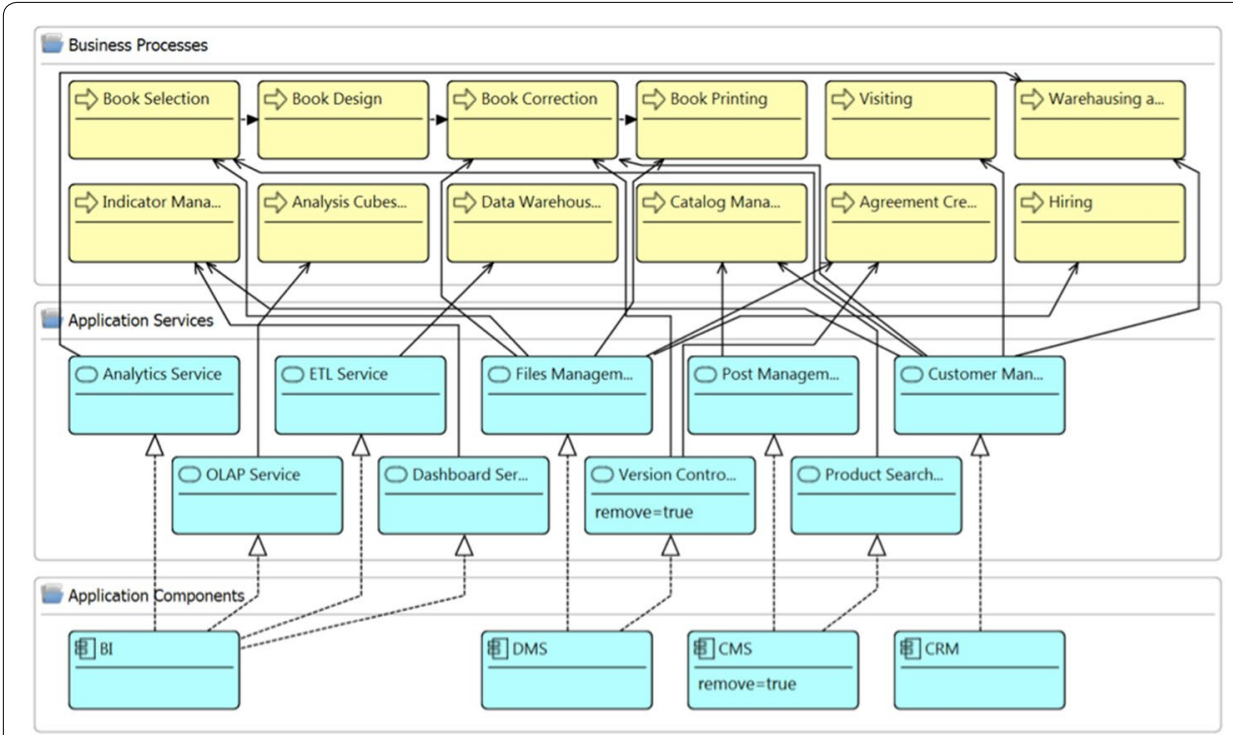

Fig. 5 Fragment of layered view of the publisher scenario. Analysis method FIC001 checks the value of the attribute remove

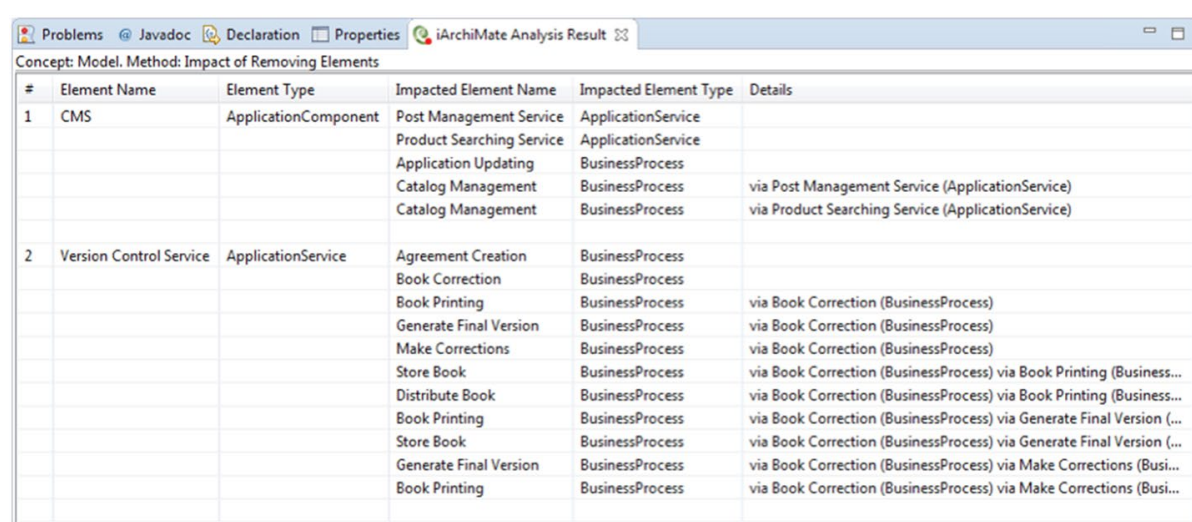

Fig. 6 Analysis results. Report of analysis method: FIC001

method illustrates the need of required attributes, the reporting of the analysis method results, and the enrichment of the model with new relations (Association between Requirement and the correspondent infrastructure elements).

Algorithm 4 calculates the results of the analysis method FIC001, where $R=$ Requirement. The algorithm iterates the requirements of the model and gets the values of the required attributes conditionAttribute, conditionoperation, conditionValue, and targetElements. For each requirement, the algorithm iterates all elements specified in targetElements. For each of those elements, the algorithm gets the value of the attribute specified in conditionAttribute and makes the comparison specified in conditionoperation with the value specified in conditionValue. If the comparison is true, the Association relation is created. 
Table 9 Automated analysis method: FCO009
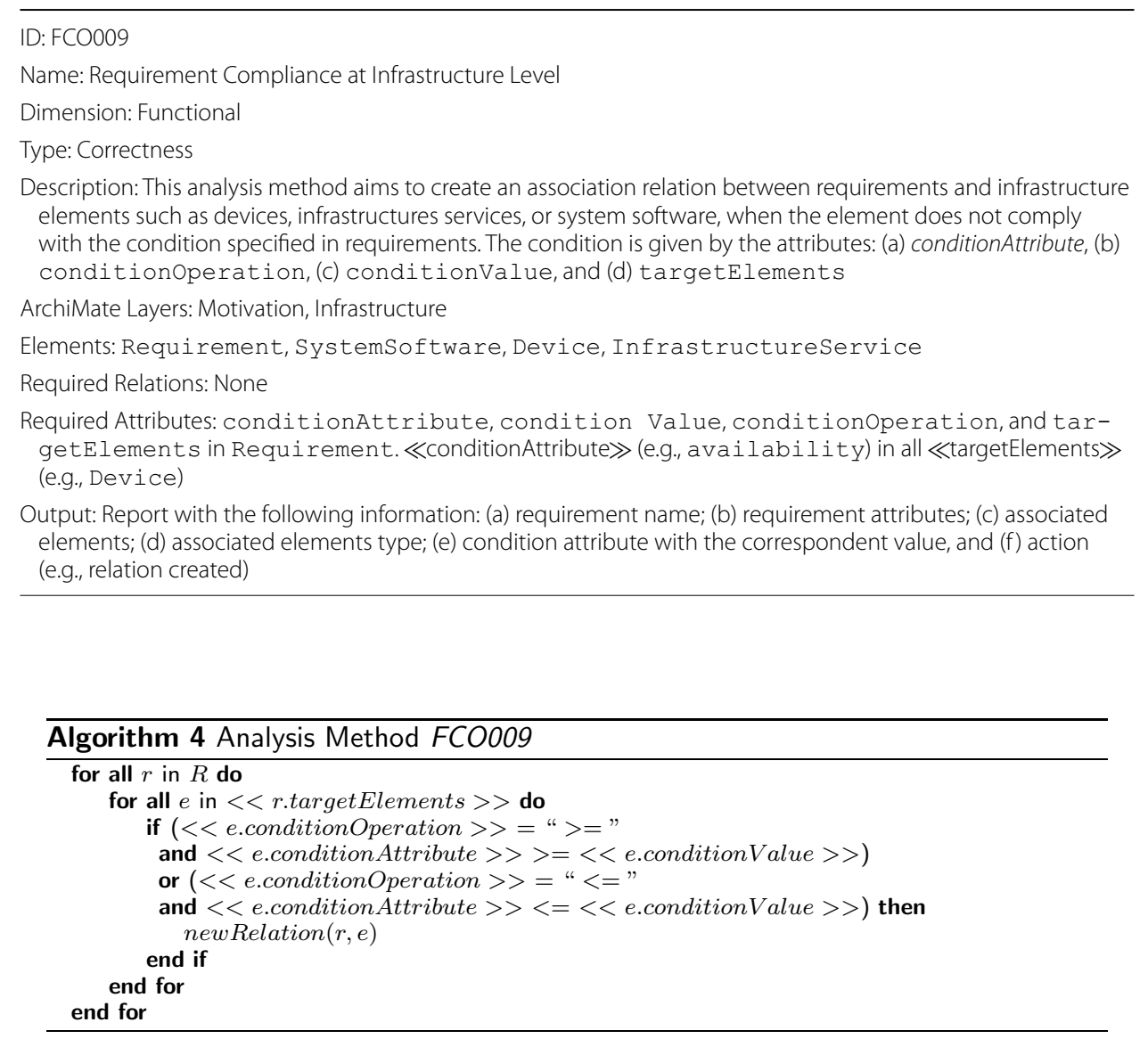

Figure 7 presents the infrastructure technology view of the enterprise model of the publisher scenario with two requirements. It contains devices, which realizes infrastructure services and aggregates system software. In addition, the model has the requirements: (1) IT High Availability with the attributes: targetElements = "Device, SystemSoftware, InfrastructureService", conditionAttribute = "availability", conditionoperation = ">=", and conditionvalue = "0.96"; and (2) IT High Storage Capacity with the attributes: targetElements = "Device, InfrastructureService", conditionAttribute = "storageUsed", conditionoperation = "<=", and conditionvalue = "100". Finally, the model has relations called impact from the requirements to some infrastructure elements. Those relations were created by the analysis method, when the attribute (e.g., availability, storageUsed) value in the element does not comply with the condition established in the requirements. Figure 8 reports the results of the analysis method. The report presents the list of the requirements with the condition attributes and the infrastructure elements specifying the relations created between requirements and elements.

\section{A tool for supporting automated analysis}

We built iArchiMate (see http://iarchimate.virtual.uniandes.edu.co), which is an enterprise modeling and analysis tool (Florez et al. 2014). The tool's core is a graphical editor 


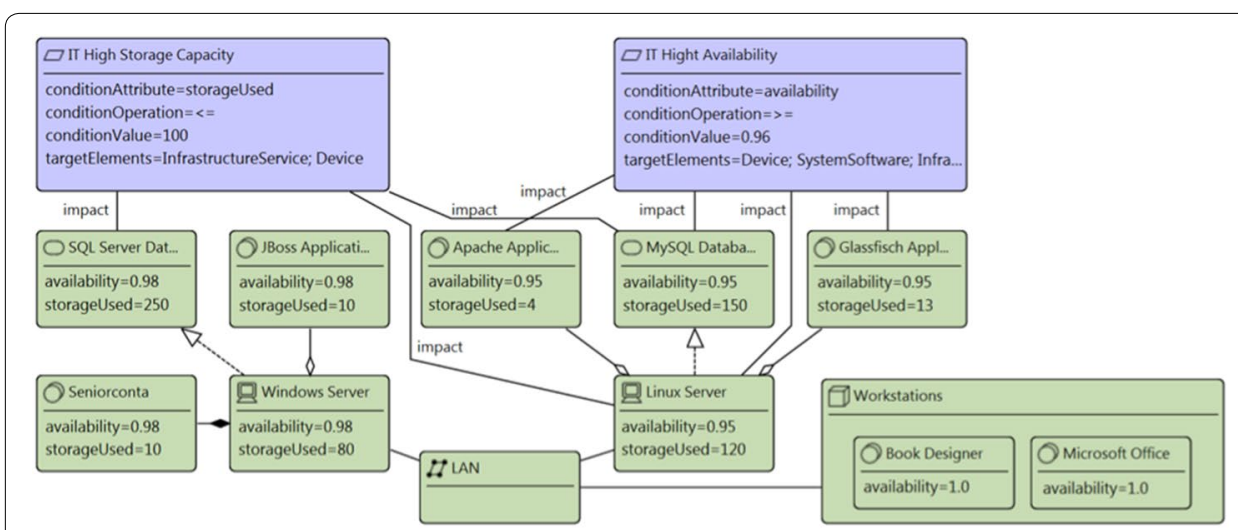

Fig. 7 Infrastructure technology view of the publisher scenario. Relations impact have been created by the analysis method FOC009

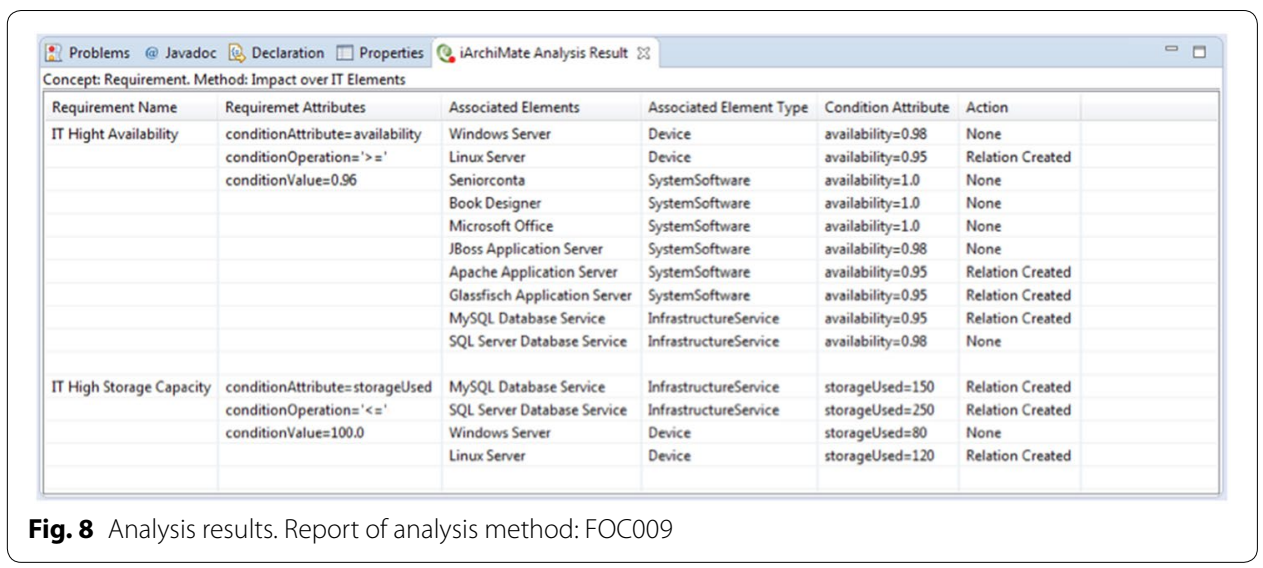

based on Eclipse Modeling Framework Project (EMF) and Graphical Modeling Framework Project (GMF). iArchiMate is capable of validating the model providing assistance to the user, in order to determine if the model fulfils the required information for running the desired automated analysis method (e.g., attribute availability in all Device for running the method QAV004). This validation is supported by Epsilon Validation Language (EVL); thus, when the desired analysis method is selected, iArchiMate generates an EVL script, for validating the model.

Moreover, iArchiMate allows importing models from other modeling tools such as Archi (see http://www.archimatetool.com). Then, iArchiMate imports the model leaving it ready to include the additional information that analyses require. Figure 9 presents a screenshot of iArchiMate and shows the Technical Infrastructure View of the enterprise model of the publisher scenario. In the left side, the package explorer allows browsing the views of the model. In right side of the graphical editor, there is the palette, which includes components for creating ArchiMate models. The tool allows selecting the ArchiMate type of elements (e.g., BusinessProcess, ApplicationComponent) and relations (e.g., UsedBy, Flow) through one attribute called typeName. At the bottom of iArchiMate, there is the properties view, which includes a tab for displaying the 


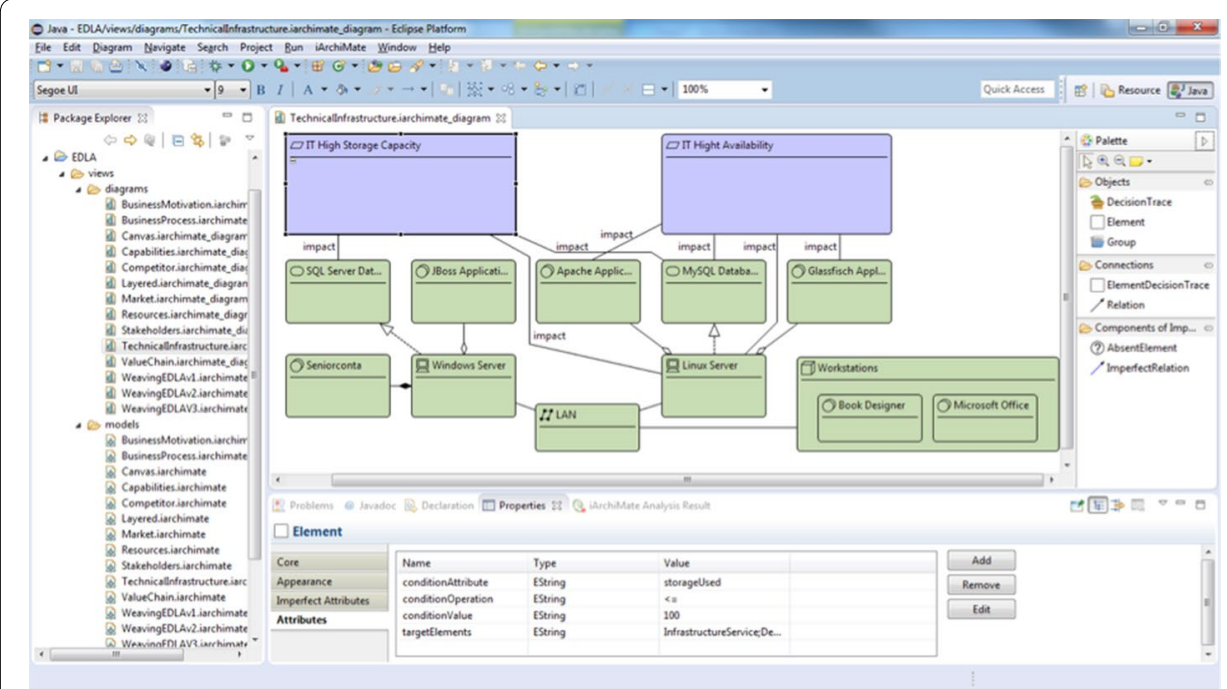

Fig. 9 Screenshot of iArchiMate. iArchiMate has in the right side a palette for drawing elements and relations and in the bottom side the Properties view and Analysis results view

attributes of the selected element or relation and the iArchiMate Analysis Result view. In addition, there is a menu, for selecting and performing analysis methods.

\section{Automated analysis methods}

Although iArchiMate can be used to create ArchiMate models, its real value is in supporting the execution of automated analysis methods. For achieving this, the modeler must select the desired analysis method, from a list of the currently deployed ones. With this information, iArchiMate generates the necessary EVL scripts, for validating the existence of all mandatory information that the method requires. After the modeling phase is finished and the validation process is successful, the analyst can run any of the enabled analysis methods and its results are collected.

If some mandatory information is not available, the method cannot be run and the problem is highlighted. The validation engine produces a warning laying it up on top of the diagram and listing it in the Eclipse Problems view. For instance, the analysis method Application Component Availability, illustrated in the previous section, requires the attribute availability in all Device; then, after selecting this analysis method, the validation engine verifies this requirement. Figure 10 presents the elements of the infrastructure group presented in Fig. 3, which corresponds to the layered view of the publisher scenario. For illustrating the validation result, the attribute availability in the Device Windows Server has been deleted from the model; consequently, a warning appears informing the problem.

\section{Results of analysis}

The results of an analysis method can have two natures. On the one hand, there are results, which are external to the model and need to be exported or visualized in a separated way. In iArchiMate, these kinds of results are visualized in a view called iArchiMate Analysis Results, which can display simple values as well as more complex tables. 


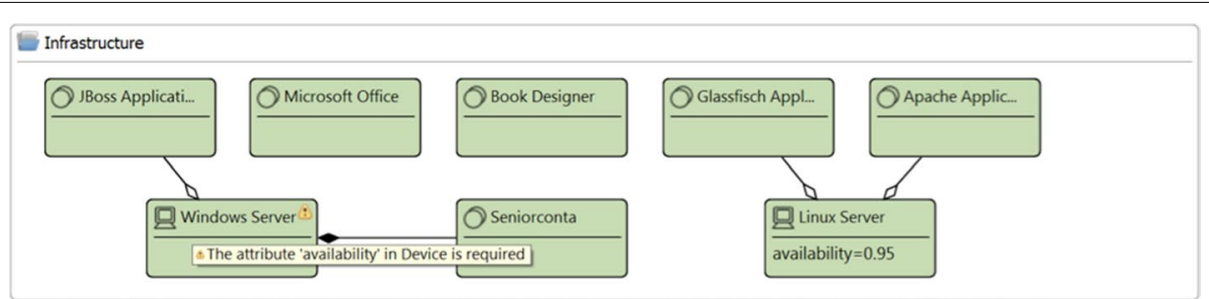

Fig. 10 Validation result. The validation provides information regarding the mandatory attributes required for a specific analysis method

On the other hand, there are analysis methods that can enrich the model. These methods may register their results as valued attributes of elements or relations, as new relations, or even as new elements. New relations and elements are highlighted in the model. Executing the automated analysis methods is not necessarily the last step in the process because new analysis methods can be selected and run at any time in order to provide additional results.

\section{iArchiMate architecture}

iArchiMate architecture (see Fig. 11) is extensible, supporting the implementation of new analysis methods, when the catalog is extended. This can be done because the architecture has one analysis component, which is the analysis core. The analysis component uses (1) the user interface component, which provides wizards, message boxes, and the analysis results view; (2) the validation component, which provides the mechanisms for creating the EVL scripts and the validation engine; and (3) the utilities components, which provides services for manipulating the model based on EMF. The creation of a new analysis method implies creating a component that uses the services exposed by the analysis component.

\section{Conclusions}

Enterprise modeling and enterprise modeling analysis are becoming increasingly important in many fields. There are some approaches that offer different alternatives for analyzing enterprise models. However, these approaches are focused on specific kinds of

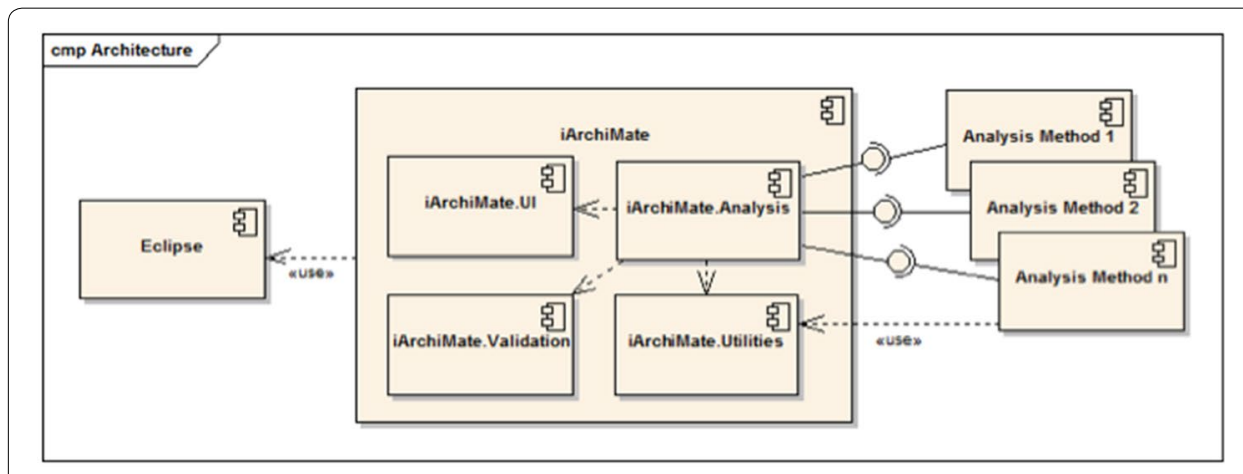

Fig. 11 iArchiMate architecture. The architecture allows including further analysis methods 
analyses; then, they usually provide a limited number of analysis methods. Based on this situation, it is unlikely to be able to cover all analysis options.

In this paper we have presented the work of compilation, classification, structuring, characterization, and unification of automated analysis methods for enterprise models. We collected these analysis methods in one catalog, which aims to offer a guide for supporting enterprise analysts in analyses processes through the description of 78 analysis methods sorted in 2 dimensions (quantitative and functional) and 16 analysis types.

The paper also presented our tool called iArchiMate in which we have implemented the analysis methods presented in the catalog, for ArchiMate models, and offers a framework for the development of additional methods. By using iArchiMate it is possible to create or import ArchiMate models; to validate models based on the analysis method that is intended to be performed; and to run the selected analysis methods, where the results can be enrich the model.

\section{Authors' contributions}

HF participated in the systematic literature review, characterization of the analysis methods, creation of the modeling tool iArchiMate, implementation of the analysis methods of the catalog in iArchiMate, and drafted the manuscript. MS participated in the characterization of the analysis methods and helped to draft the manuscript. JV participated in the characterization of the analysis methods and helped to draft the manuscript. All authors read and approved the final manuscript.

\section{Authors' information}

HF is Ph.D. student in Engineering at the Universidad de los Andes, Bogotá, Colombia. His research interests are: enterprise modeling, model driven engineering, and enterprise analysis. MS is an Assistant Professor of the Department of Systems and Computing Engineering at the Universidad de los Andes, Bogotá, Colombia. He is Ph.D. in Engineering at the Universidad de los Andes. His research interests are: enterprise architectures, and executable models. JV is an Associate Professor of the Department of Systems and Computing Engineering at the Universidad de los Andes, Bogotá, Colombia. He is Ph.D. in Informatics at the Université Joseph Fourier, Grenoble, France. His research interests are: enterprise modeling and software design.

\section{Acknowledgements}

We want to thank the research group TICSw from the Universidad de los Andes.

\section{Competing interests}

The authors declare that they have no competing interests.

Received: 17 September 2015 Accepted: 18 March 2016

Published online: 02 April 2016

\section{References}

Akkary H, Driscoll MA (1998) A dynamic multithreading processor. In: 31st Annual ACM/IEEE international symposium on microarchitecture. IEEE Computer Society Press, pp 226-236

Angelov S, Grefen P, Greefhorst D (2009) A classification of software reference architectures: analyzing their success and effectiveness. In: European conference on software architecture. IEEE, pp 141-150

Armistead C, Pritchard J-P, Machin S (1999) Strategic business process management for organisational effectiveness. Long Range Plann 32(1):96-106

Berander P, Damm L-O, Eriksson J, Gorschek T, Henningsson K, Jönsson P, Kågström S, Milicic D, Mårtensson F, Rönkkö K et al (2005) Software quality attributes and trade-offs. Blekinge Institute of Technology, Blekinge

Bollobás B (1982) Graph theory. Elsevier, Amsterdam

BuckI S, Matthes F, Schweda CM (2009) Classifying enterprise architecture analysis approaches. Enterp Interoper 38:66-79

Davenport TH, Short J (1990) The new industrial engineering: information technology and business process redesign. Sloan Manag Rev 31(4):11-27

Di Penta M, German DM, Guéhéneuc Y-G, Antoniol G (2010) An exploratory study of the evolution of software licensing. In: 32nd ACM/IEEE international conference on software engineering. ACM, pp 145-154

Donoso Y (2009) Network design for IP convergence. CRC Press, Boca Raton

Fischer R, Aier S, Winter R (2007) A federated approach to enterprise architecture model maintenance. Enterp Model Inf Syst Archit 2(2):14-22

Florez H, Sanchez M, Villalobos J (2014) iArchiMate: a tool for managing imperfection in enterprise models. In: 18th IEEE international enterprise distributed object computing conference workshops and demonstrations, pp 201-210

Florez H, Sanchez M, Villalobos J (2014) Extensible model-based approach for supporting automatic enterprise analysis. In: 18th IEEE international enterprise distributed object computing conference (EDOC), pp 32-41 
Frank U (2014) Multi-perspective enterprise modeling: foundational concepts, prospects and future research challenges. Softw Syst Model 13(3):941-962

Guadamuz A (2001) Habeas data vs. the European data protection directive. J Inf Law Technol 3:1-18

Gómez P, Sánchez M, Florez H, Villalobos J (2014) An approach to the co-creation of models and metamodels in Enterprise Architecture Projects. J Object Technol 13(3):1-29

lacob M-E, Jonkers H (2006) Quantitative analysis of enterprise architectures. In: Konstantas D, Bourrières J-P, Léonard M, Boudjlida N (eds) Interoperability of enterprise software and applications. Springer, London, pp 239-252

Johnson P, Johansson E, Sommestad T, Ullberg J (2007) A tool for enterprise architecture analysis. In: 11th IEEE international enterprise distributed object computing conference, pp 142-142

Kitchenham B, Brereton OP, Budgen D, Turner M, Bailey J, Linkman S (2009) Systematic literature reviews in software engineering —a systematic literature review. Inf Softw Technol 51(1):7-15

Kitchenham B, Pretorius R, Budgen D, Brereton OP, Turner M, Niazi M, Linkman S (2010) Systematic literature reviews in software engineering - a tertiary study. Inf Softw Technol 52(8):792-805

Kofman A, Yaeli A, Klinger T, Tarr P (2009) Roles, rights, and responsibilities: better governance through decision rights automation. In: 2009 IEEE workshop on software development governance. IEEE Computer Society, pp 9-14

Lam W (2002) Ensuring business continuity. IT Prof 4(3):19-25

Lankhorst M (2005) Enterprise architecture at work: modelling, communication and analysis. Springer, Berlin

Lisboa LB, Garcia VC, Lucrédio D, de Almeida ES, de Lemos Meira SR, de Mattos Fortes RP (2010) A systematic review of domain analysis tools. Inf Softw Technol 52(1):1-13

Menascé DA, Bennani MN (2006) Analytic performance models for single class and multiple class multithreaded software servers. In: International CMG conference. Citeseer, pp 475-482

Quartel D, Steen MWA, Lankhorst M (2010) It portfolio valuation-using enterprise architecture and business requirements modeling. In: 14th IEEE International enterprise distributed object computing conference. IEEE, pp 3-13

Sandkuhl K, Stirna J, Persson A, Wißotzki M (2014) Enterprise modeling: tackling business challenges with the 4EM method. Springer, Berlin

Schmidt K (2006) High availability and disaster recovery: concepts, design, implementation, vol 22. Springer, Berlin

Somasundaram G, Shrivastava A (2009) Information storage and management. Wiley, Hoboken

Sunkle S, Kulkarni V, Roychoudhury S (2013) Analyzing enterprise models using enterprise architecture-based ontology. In: Model-driven engineering languages and systems. Springer, Berlin, pp 622-638

The Open Group (2012) ArchiMate 2.0 specification. Van Haren Publishing, Berkshire

The Open Group (2011) TOGAF Version 9.1. Van Haren Publishing, Berkshire

Zachman J (2006) The Zachman framework for enterprise architecture. Zachman Framework Associates, Virginia

\section{Submit your manuscript to a SpringerOpen ${ }^{\circ}$ journal and benefit from:}

- Convenient online submission

- Rigorous peer review

- Immediate publication on acceptance

- Open access: articles freely available online

- High visibility within the field

- Retaining the copyright to your article

Submit your next manuscript at $\mathbf{s p r i n g e r o p e n . c o m ~}$ 